\title{
University students' perceptions of social networking sites (SNSs) in their educational experiences at a regional Australian university
}

\author{
Christina Sadowski, Mika Pediaditis and Robert Townsend \\ Federation University Australia
}

\begin{abstract}
Higher education institutions, and the way education is delivered and supported, are being transformed by digital technologies. Internationally, institutions are increasingly incorporating online technologies into delivery frameworks and administration - both through internal learning management systems (LMS) and external social networking sites (SNSs). This study aims to explore how higher education students in a regional Australian dual-sector institute use and manage SNSs for personal and study-related activities and their perceptions of how this impacts their educational experiences. This mixed-methods study involved a quantitative and qualitative survey of 355 vocational training and higher education students and in-depth focus groups with ten higher education students. Four key themes were identified through thematic analysis: SNSs as a tool for fostering peer connectedness with fellow students; deliberate and distinct variation between personal and educational use of SNSs; resistance to external SNSs within education settings; and, need for a balance between digital and face-to-face learning and connectedness. Implications for curriculum design and delivery, and development of support for students in diverse learning contexts, are considered.
\end{abstract}

\section{Introduction}

Internationally, higher education faces intense pressure and change as a result of forces of globalisation, competition and commercialisation (Global Agenda Council on the Future of Universities, 2012). The rise of digital technologies is seen as a major force revolutionising universities' learning and teaching models (Ernst \& Young, 2012; Global Agenda Council on the Future of Universities, 2012). In their report about the future of universities, Ernst and Young (2012) predict that although the digital revolution will not eradicate campus-based universities, it will transform how education is delivered and supported, and the way higher education institutions create value. Overwhelmingly, universities use learning management systems (LMSs), which are defined as "an online course space to share information and resources with students and manage student learning by structuring pathways through content and activities” (Federation University Australia, n.d., para 1) to support blended learning activities. At December 2015, Moodle, the most used LMS, had nearly 80 million users, followed by Edmodo with 49 million users (Capterra, n.d.). The regional Australian university from where this research emanates uses Moodle, with students automatically enrolled in course-specific Moodle shells.

Although LMSs support universities to develop, manage and deliver blended learning, their value has been questioned amidst the dominance of social networking sites (SNSs) such as Facebook (Irwin, Ball, Desbrow, \& Leveritt, 2012). SNSs are defined as "an online platform that allows users to create a public profile and interact with other users on the website” (Social Networking Site, 2016). Robbins and Singer (2014) provide a useful overview of different streams of social media platforms for sharing: short-form writing or micro-blogging (Facebook, Twitter, Google Plus), long-form writing or blogging (WordPress, Tumblr, Blogger), images (Snapchat, Pinterest, Instagram), videos (Vine, YouTube), audio programs/podcasts (iTunes, Stitcher), as well as synchronous communication tools (Skype, Google Hangouts, Second Life) and SNSs specifically for professionals (LinkedIn), some specifically targeting academics (ResearchGate, Academia). These diverse SNSs vary in their emerging cultures, with variations in network membership such as diverse membership versus membership by commonality in identity; focus on maintaining pre-existing social networks versus facilitating connections based on shared interests; plus the incorporation of new information and tools for communication (i.e., mobile connectivity, video or photo sharing) (boyd \& Ellison, 2007).

This study was part of a larger research project at a regional Australian dual-sector institute with campuses across regional Victoria. Within the context of an institutional learning and teaching plan which outlines a strategy to explicitly enhance blended, online and digital (BOLD) learning (Devlin, 2015), the study was 
conceptualised to explore three interrelated lines of enquiry: (1) students' peer interaction as learners within diverse delivery modes; (2) students' use of campus spaces and perceptions about delivery modes; (3) students' educational and personal engagement with SNSs. This article presents the findings on the third line of enquiry. Specifically, it considers how students use and manage LMSs and multiple SNSs for personal and educational activities and students' perceptions on how this usage impacts their educational experiences. Ideally, this study will contribute to growing knowledge about how to harness the possibilities of rapidly advancing technology to enhance the learning opportunities for today's (and tomorrow's) university students.

\section{Literature review}

Statistics suggest that $68 \%$ of Australian Internet users have an SNS presence, with 24\% checking at least five times per day (Sensis, 2015). Facebook is the most used SNS in the world, with Facebook (2016) reporting a staggering 1.13 billion daily active users across the globe as at June 2016. Fifteen million Australians used Facebook in March 2016 (Cowling, 2016), with this SNS used by 93\% of all Australian users in 2015, who spent an average of 8.5 hours per week accessing the site (Lord, 2016). Nearly as many Australians (14.2 million) accessed YouTube during this time period (Cowling, 2016).

A growing body of literature explores the use of SNSs in higher education (Kurkela, 2011; Maloney, Moss, \& Ilic, 2014; Peck, 2014; Tess, 2013; Usher et al., 2014; Wang, Tchernev, \& Solloway, 2012). In recognition of a lack of empirical evidence about the efficacy of SNSs in higher educational settings, Tess (2013) conducted a literature review of research. He notes that the majority of studies investigating learning outcomes and student achievements in relation to SNSs in educational settings report positive outcomes. For example, a study of 50 online graduate students using Ning (Brady, Holcomb, \& Smith, 2010) reveals students' positive perceptions of the capacity of Ning to make communication with other students more possible than face-to-face delivery (70\%), communicate with peers outside of class (82\%) and reflect and comment on peers' work more effectively than within a face-to-face setting (74\%). However, the findings of other studies are not as positive, with a cross-institutional study by Jones, Ramanau, Cross, and Healing (2010) suggesting that students rarely use SNSs for educational purposes. Tess (2013) reaches the conclusion that there is insufficient research evidence to definitively state whether SNSs are an "efficient and effective software solution for the higher education classroom” (p. 66).

Not surprisingly given its popularity, much research attention has been paid to Facebook (Cuesta, Eklund, Rydin, \& Witt, 2015; Irwin et al., 2012; Kabilan, 2016; Madge, Meek, Wellens, \& Hooley, 2009; Ratneswary \& Rasiah, 2014; Santos \& Cuta, 2015; Vivian, Barnes, Geer, \& Wood, 2014). Manca and Ranieri (2013) conducted a literature review of 23 peer-reviewed articles focusing on Facebook as a learning environment to explore "the extent to which its pedagogical potential is translated into practice" (p. 487), explicating three themes: instructional efficacy; supportive and interactive learning tool; and students' reactions to Facebook as an instructional tool. Although 11 studies exploring instructional efficacy report positive outcomes, findings about Facebook as a supportive and interactive learning tool were mixed. Although some studies argue that Facebook increases learner participation, encourages discussion and information exchange, other studies highlight students' reluctance to engage with Facebook in the educational setting. Likewise, studies exploring students' reactions to Facebook as an instructional tool provide mixed results.

Facebook's capacity to enhance student learning is reinforced in a number of studies. For example, in their study of 24 students participating in a closed Facebook forum, Cuesta et al. (2015) found that forum participation enhances the understanding of academic culture and knowledge production of higher education students from diverse backgrounds. Ratneswary and Rasiah (2014) highlight Facebook's capacity to enhance teaching and learning in team-based environments by providing innovative ways of involving and motivating students. Facebook's capacity to facilitate positive peer connections is a strong and consistent theme across the literature (Irwin et al., 2012; Madge et al., 2009; Santos \& Cuta, 2015). In their study of 501 students from different nationalities, Santos and Cuta (2015) conclude that "social networks are the modus operandi of the new generation", with their findings suggesting that Facebook helps students to "accumulate and maintain bridging social capital" (p. 41). 


\section{Method}

The study was conducted at a regional Australian dual-sector higher education institute between September 2014 and April 2015, with students from all campuses and domestic partner institutes, delivery modes (faceto-face, blended and on-line) and level of study (vocational, undergraduate and postgraduate) invited to participate via emails sent out to all students. Human research ethics was granted from the university's Human Research Ethics Committee (HREC) in August 2014 (HREC code B14-048).

\section{Participants}

A total of 355 students participated in the mixed-methods online survey. Participants were disproportionately female (71\%, compared with $29 \%$ male) when considering the university's gender mix of $55 \%$ female and $45 \%$ male. The age profile of participants was distributed across age categories $(46 \%$ $18-25,18 \% 26-34,23 \% 35-44$, and $13 \% 50$ years and over). Mode of delivery reflected the university's multimodal delivery options, with $54 \%$ students studying face-to-face, $35 \%$ identifying blended mode (face-to-face and online) and $11 \%$ online/distance education. The majority of students were full-time students (67\% full-time, 33\% part-time). Students represented a diverse range of programs (arts, humanities, social sciences, education, psychology, health sciences, engineering).

Additionally, 10 students from undergraduate programs who self-selected into the research project (promoted through flyer distribution, invited presentations during lectures and the university residential social media page) participated in three focus groups conducted in September and October 2014, involving semi-structured qualitative interviews. These students were all full-time, with 8 in the 18-25 age bracket and two aged $35-44$ years.

\section{Survey and focus groups}

The online survey consisted of 30 quantitative questions, with seven of these questions inviting optional qualitative comments. Five questions related to demographic information (age, gender, mode of study) and 12 questions related specifically to the line of enquiry reported here. Of these 12 questions, five questions invited optional open-ended qualitative comments, generating 525 qualitative responses. Questions focused on use of SNSs, specific SNS accounts used, most frequently used SNSs, frequency of use (including how many times per day), length of usage per day, reason for using SNSs, SNSs used in relation to studies and how these are used, difference between use of SNSs in studies and personal life, how SNSs were used as part of curriculum, and ways that SNSs could enhance educational experience/processes.

Focus groups involved semi-structured qualitative interviews, with questions about the use of SNSs (number of accounts, patterns of use, i.e., frequency, duration and purpose) and perceptions of how SNSs impact their educational experiences. Focus groups were conducted by a final-year social sciences student completing a capstone research project, and were supervised by one of the staff researchers.

\section{Data analysis}

Thematic analysis (Braun \& Clarke, 2006) was utilised in this study to identify, analyse, interpret and report on themes located in the focus group and online qualitative data sets. Thematic analysis aims to expose meaning in the data by ascertaining and evaluating themes (Buetow, 2010) found in qualitative methodology, such as discussions in interviews and focus groups about experiences pertaining to the research question (Aronson, 1994). This study followed Braun and Clark's (2006) six steps of thematic analysis: (1) becoming familiar with the data and transcribing all data; (2) generating codes; (3) classifying codes into themes; (4) reviewing and refining themes; (5) concisely defining and naming themes; (6) producing a report from the thoroughly worked themes which is a descriptive, analytical and argumentative narrative.

Fereday and Muir-Cochrane (2006) highlight the importance of the scrutiny of data analysis, code assignment, and theme clustering and development, and the need for multiple iterations of these processes within thematic analysis to ensure credibility. Two members of the research team (an experienced researcher and a student researcher) conducted the initial data analysis and code assignment separately to ensure reliability. The third member of the team (an experienced researcher) reviewed this initial iteration, 
with all members of the research team developing the emergent themes separately before collectively finalising the themes based on their re-examination of the data, codes and final themes.

Direct quotations from participants (written from online survey participants and verbal from focus group participants) are included to elucidate key themes.

\section{Results}

The results are presented in two sections. The first section reports quantitative data about students' use of SNS, including reported SNS usage (site use and frequency) and purpose of SNS usage (personal and educational). The second section reports emergent themes about students' use and management of SNSs in their personal and educational lives and their perceptions of how this usage impacts their educational experiences were explicated through the process of thematic analysis. Themes include:

- SNSs as a tool for fostering peer connectedness with fellow students

- deliberate and distinct variation between personal and educational SNS use

- resistance to SNS within education settings

- need for a balance between digital and face-to-face learning and peer connectedness.

\section{Quantitative data from online surveys}

Reported SNS usage - site use and frequency

The vast majority ( $n=303,89.38 \%)$ report using SNSs online. Facebook was the dominant SNS, both in regards to account membership $(n=289$ 86.53\%) and most used site $((n=269,80.3 \%)$. Table 1 identifies the specific SNSs with which participants report having an account.

Table 1

SNS accounts

\begin{tabular}{lll}
\hline SNS & $\begin{array}{l}\text { Percentage who report having an } \\
\text { account with this site }\end{array}$ & Totals \\
\hline Facebook & $86.53 \%$ & 289 \\
YouTube & $50.30 \%$ & 168 \\
Google+ & $32.63 \%$ & 109 \\
Twitter & $28.44 \%$ & 95 \\
Instagram & $32.93 \%$ & 110 \\
LinkedIn & $24.85 \%$ & 83 \\
Pinterest & $23.35 \%$ & 78 \\
Tumblr & $12.28 \%$ & 41 \\
No accounts & $5.09 \%$ & 17 \\
Digg & $0.30 \%$ & 1 \\
Other & $4.49 \%$ & 15 \\
\hline
\end{tabular}

Table 2 lists the most frequently used sites. (Note: Some participants reported using multiple sites.)

Table 2

Most frequently used SNSs

\begin{tabular}{lll}
\hline SNS & $\begin{array}{l}\text { Percentage who report using this site } \\
\text { frequently }\end{array}$ & Totals \\
\hline Facebook & $80.30 \%$ & 269 \\
You Tube & $24.78 \%$ & 83 \\
Instagram & $22.39 \%$ & 75 \\
Google+ & $9.55 \%$ & 32 \\
Pinterest & $8.66 \%$ & 29 \\
None & $7.76 \%$ & 26 \\
Tumblr & $7.46 \%$ & 25 \\
Twitter & $7.16 \%$ & 24 \\
Other & $3.28 \%$ & 11 \\
\hline
\end{tabular}


Participants identified a diverse range of additional SNSs not identified in the survey choices, including Ymail, WeChat, wellbo, Snapchat, Line, Kakao Talk, fanfiction.net, Yahoo, Gmail, Flickr, Steam, Battlenet, ResearchGate, QQ, Behance, Reddit and SoundCloud.

The overwhelming majority of participants reported checking their SNS accounts every day (76.92\%, $n=$ $250)$, with a further $12.92 \%(n=42)$ checking once every few days, $2.46 \%(n=8)$ checking once a week, $0.62 \%(n=2)$ once every few weeks, $0.92 \%(n=3)$ once a month and 6.15\% $(n=20)$ checking 'rarely'. Of the 279 students who reported accessing SNSs every day, 13.98\% $(n=39)$ checked once, $7.89 \%(n=$ 22) checked twice, 43.73\% $(n=122)$ checked 'a few times', 8.24\% $(n=23)$ every hour and $26.19 \%(n=$ 73) checking 'whenever I can'. These responses indicate that a significant percentage of the students surveyed (78.16\%) access their SNSs multiple times a day.

Of the 311 students who responded to the question, 'How often do you spend during an average day looking at SNS?', a total of $68.49 \%$ reported spending less than 60 minutes per day (with $34.41 \%, n=107$ ) reporting "less than 30 minutes a day" and 34.48\% $(n=106)$ reporting 30-60 minutes per day. The remaining participants reported more frequent use $(16.08 \%, n=50)$ at $1-2$ hours per day, $9.97 \%(n=31)$ at $2-4$ hours per day, $4.50 \%(n=14)$ at $4-6$ hours per day and $0.96 \%(n=3)$ at more than 6 hours per day. Nearly onethird of students (31.51\%) reported spending more than one hour per day looking at SNSs.

Purpose of SNS usage - personal and educational

Connection with friends and family and for entertainment were reported as the dominant reasons for using SNSs. The 329 participants who responded to this question were able to choose multiple responses. The most popular reason $(77.81 \%, n=256)$ was "keeping in touch with friends", followed by "entertainment" $(64.13 \%, n=211)$, "keeping in touch with family" $(63.22 \%, n=208)$, "accessing local or world news" (48.02\% $n=158)$, "gain knowledge/educational purposes" (45.59\%, $n=150)$, "follow and participate in specific personal interests” $(42.86 \%, n=141)$, “accessing celebrity news” $(10.33 \%, n=33)$, “forming your identity profile” $(8.81 \%, n=29)$ and "gambling” $(4.26 \%, n=14)$. A total of $6.99 \%$ of participants $(n=23)$ responded with "I don’t use social media or social networking.”

Participants were asked about their use of SNSs specifically in relation to their studies. A majority (59.25\%, $n=189)$ responded “yes,", with the remaining 33.23\% $(n=106)$ responding "no" and 7.52\% $(n=24)$ responding 'not sure.' Two hundred and twenty-three participants answered the follow-up question, "If you use SNS for your studies, do you use these for any of the following?” The overwhelming response was "connect[ing] to peers/other students" $(77.13 \%, n=172)$, followed by "connect to content (Moodle)" (56.50\%, $n=126)$. Of the participants, 32.74\% $(n=73)$ use SNSs to "assess current research/information pertaining to your studies,", $29.60 \%(n=66)$ to “connect to teaching staff” and $18.83 \%(n=42)$ to "connect to admin or students services.”.

One hundred and eighty-four participants answered the question, "Is the way you use SNS for your studies different from how you use it in your personal life? Describe the difference.” Just over half (57.07\%, $n=$ 105 responded "yes” and 22.28\% $(n=41)$ responded "no". The remaining 58 participants provided diverse responses, such as “don't use” (9.78\%, $n=18)$ and “only use for study” $(5.98 \%, n=11)$.

Participants were asked to comment on the potential usefulness of SNSs at the course or program level to enhance a range of processes. Of the 300 students who responded to this question, 64.52\% $(n=140)$ identified "peer/student connectedness", 42.40\% $(n=92)$ identified "connecting and accessing academic teaching staff', 34.56\% $(n=75)$ identified “accessing the latest research/discipline studies”, 24.42\% ( $n=$ 52) identified "links to other learning platforms like TED talks or MOOCS", $18.43 \%(n=40)$ identified "future employability" and $12.9 \%(n=28)$ identified "there is very little educational benefit to social media.”.

\section{Explication of themes}

Four key themes were identified through the process of thematic analysis and are elucidated through students' direct quotations. 
SNSs as a tool for fostering peer connectedness with fellow students

As highlighted in the quantitative data reported above, of the $59.25 \%$ of students $(n=189)$ who reported using SNSs specifically in relation to their studies, $77.13 \%(n=172)$ identified their purpose as "connect[ing] to peers/other students". For some students, Facebook groups provided a way to connect with peers for study-related purposes:

Many courses have [F]acebook groups that allow students to ask the student body of that course any questions about the class, assessments, dates.

Like the online survey respondents, focus group participants overwhelmingly identified Facebook as the chief source of connecting with fellow students. They saw Facebook as a way to connect with fellow students, coordinate group projects and network with students in their course, program or the broader university community (such as clubs and societies).

The benefits of the immediacy of responses to questions about assessment tasks or course requirements from their peers ("It's a lot easier than having to run around after teachers"), particularly with studentdeveloped course-specific pages ("the whole cohort is on that Facebook page so you get at least ten people responding when you have a problem”). Another student commented on the quickness of response times from peers through SNSs, as compared to waiting for an academic to respond:

Academics take too long to respond, whereas posts on FB are replied to within minutes (when you need clarification or help)

Although for some students connecting with peers seemed to have a primarily educational focus, for others it also involved social aspects. A mature-age student commented on how SNSs provided positive opportunities to connect with her peers:

[S]ocial media ... helps me connect, engage and learn from and with younger students while incorporating my personal life.

For a cohort of students, SNSs were seen as having potential benefits of facilitating peer connections and overcoming feelings of isolation and disconnection for online students, or those who come infrequently to campus:

It is extremely difficult for online students to stay engaged without any peer contact. Online students are highly disadvantaged and this needs to be addressed.

It would be good to connect with other online students so we could discuss our studies, have conversations and support each other since we are all going through the same things but I don't know any other online students. It would be good if on moodle or facebook there was a social group for just online students where we could support, study and talk to each other.

Deliberate and distinct variation between personal and educational SNS use

In the quantitative survey, over half of respondents (57\%) identified that their use of SNSs for study purposes is different from their personal usage. Those who responded affirmatively referred to differences between study and personal use, making explicit distinctions between their "personal" and the "professional/study" use of SNSs on two levels: firstly, the purpose of the interaction, and secondly the "image" presented to others.

Participants delineated between their intentional purposes of using SNSs for "personal use” ("socialising”, "social interaction", "entertainment", "posting holiday pictures", "relaxation") as opposed to "professional/study use" ("research and assessment purposes", "communicating with group members about group work assignments", and "getting information [about coursework]", "exchang[ing] information"). Whilst personal use is described as "social," "informal", and associated with personal interests and entertainment, the educational use is described as "rigorous", "professional”, "precise”, "focused", "taskoriented", and "formal": 
Yes, very different since with personal life you focus on everyday activities, you communicate regarding the relationship with the other people. If I use it for studies then the topics would be about the lessons, clarification of what was learned

When using social media for Uni, it's purely for professional reasons, whereas using it in my personal life it's all about socialising and entertainment.

When using social media for studies, I go in with a clear objective of what I need to achieve. When used personally it's really just bored meanderings.

Several participants identified different motivations/levels of enjoyment associated with SNS usage:

Yes. One is only for the requirements for study. The other is to chat and catch up with friends and family

For study, it's all just about contacting the others in your groups rather than discussing anything else. I wouldn't be "friends" with these people if it wasn't for the group work purpose.

Participants identified their presentation of different images of themselves, explicitly articulating a deliberate dichotomy (such as "personal" versus "professional", "relaxed and informal" versus "serious". One participant identified using different "personalities" depending on the purpose of the interaction, revealing "[m]y personalities are different depending on what I am after”, As one participant summarised:

The use of a private facebook group with peers for a group assignment is different from posting holiday pictures, because it's 'less personal'. It's a different image of yourself.

Several participants acknowledged that fellow students they connect with in relation to their studies were not people they would be otherwise be communicating with in their personal lives. Their connections serve a particular purpose, and the type of communication reflects this.

A small number of participants highlighted their preference for the complete separation of personal and professional/study use of SNS:

Social media needs to be completely separate from formal studies

To achieve this aim, some students identified using different SNS sites for different purposes (while some students reported using Facebook, Instagram and Snapchat for social use, others reported using LinkedIn, Instagram, Facebook, Google+ or Moodle for educational use). One student achieved separation by using specifically formed closed Facebook groups for study purposes.

Another participant reported using SNS in a business-like manner for both personal and study usage:

Not particularly, I would interact with the uni's ICT FB page the same way I would interact with the page of any company or other group. They both offer avenues for feedback, complaints, compliments etc

A participant who identified no difference signified multiple layers of SNS use with classmates (practical study purposes and more socially oriented purposes):

Not particularly. When connecting with my fellow class mates, we discuss the current assignments, but also socially connect (i.e, send each other meme's and funny videos).

Resistance to SNSs within education settings

Some students reflected an attitude of feeling "coerced" into using SNSs for study purposes. For example, one student commented "Had [author's emphasis] to use Facebook for groupwork, but not for personal use”. For other students, their acknowledgement of SNSs' usefulness for peer connections was tinged with a hint of reluctance: 
[i]f i [sic] was not at uni, i would use social media a LOT less than i do

I access social media sites in order to stay up-to-date with things. I don't personally like social media, but there is no denying that it is a means whereby to stay in touch with people while I am off-campus.

The significant and primary SNS (Facebook) used by focus group participants was recognised as a social media umbrella that is interconnected with other SNSs. Within each of the three focus groups, participants acknowledged that their use of Facebook was driven by the convenience of others utilising this platform, the no-cost aspect and the habits generated:

I wouldn't have it if people would not use Facebook messaging to contact me but people do so that's why I keep a Facebook account

While these students expressed their reluctance to use SNSs for educational purposes, other students were more explicit in their resistance to the use of external SNSs within educational settings. A small minority of students highlighted strong philosophical reasons for rejecting SNSs. For some, this related to concerns about surveillance and security:

[e]very social network websites [do] massive surveillance therefore I reject all social media.

I use email and personal contact. Social media is "unsafe" because of its public nature and also the footprint it leaves - personal security issues!

Other concerns related to the perception that SNSs should be used purely for social purposes ("social media should be just that, social") and that it erodes social skills and communication ("social media causes stresses and lack of social communication skills"). For others, the concerns were moral:

Contact with other people and sharing ideas is essential to a healthy society. We are supposed to be more connected through social media but people are not present or attending to their immediate environment because they are distracted by what is happening somewhere in a parallel universe or wasting precious time trying to make technology deliver the overrated goods.

A minority of students expressed their preference for academic and university staff to communicate through official channels (email, or the course Moodle shell), raising a desire to keep their personal and study lives separate and concerns about invasion of privacy, as well as potential for misinformation:

I find that social media is a personal thing and not something that should be used by tutors and lecturers to communicate with students. If they want to send us links to something interesting or have a discussion, they should do it via email, in class or moodle. I also find that it may be a privacy issue. Some students have added tutors/lecturers on facebook due to these groups (you have to be friends with people to add them to a group), which I [sic] find it incorrect and an invasion of privacy.

I think email and moodle are better than social media for university information as it keeps it personal and private, limiting access to the student's colleagues. Social media is great as a peripheral way of connecting outside of the university but any learning online from the university should be in a restricted online zone just for students.

Several students highlighted concerns about "blurred boundaries" and "conflicts of interest" when staff and students interact on external SNS, and become "friends" on each other's personal SNS pages:

[I]f all of it was on social media a blurred line would be created between the staff and the students 
Two of my lecturers/tutors have started [F]acebook groups to share information outside of university but still in the subject matter. There has been some discussion but I didn't participate as I find it odd to communicate with a tutor on [F]acebook, a personal site. I would rather do it on [M]oodle or email. They both posted a number of links relating to the subject, with one spamming us. That meant a lot of people were turned off participating.

Additionally, concerns were raised about potential barriers for students without adequate financial resources, and reinforcing a socioeconomic divide:

If you make it so that things are online you force people to have to have access to a laptop/computer and internet, something that can break and, in the case of sites like moodle, is often down for maintenance. This will create a further divide between those students who have financial support and those who are already struggling to make ends and forces them to lose the 24 hour access their peers enjoy.

Several focus group participants challenged the assumption that all university students have unlimited access to computers and Internet connections, commenting, "sometimes I access the 24 hour labs so I can use the internet," and "my computer is in the kitchen [of the family home] so it's hard to hear."

Need for a balance between digital and face-to-face learning and peer connectedness

When asked to provide general comments related to the research study, many acknowledged that the positive potential for SNSs in educational settings (mainly encouraging peer connectedness) needs to be balanced with the preservation of face-to-face teaching and contact with other students. While one student stated, "You can not [sic] remove the face to face component of University," others expanded on the importance of face-to-face contact for educative and social reasons:

I believe social media is beneficial for learning at uni however it shouldn't be replaced with on campus studies as everyone I believe needs personal contact with peers to keep the stress levels down.

I think that it is essential to have face-to-face contact with lecturers and peers, not only is it essential in forming relationships but is also beneficial to studying and not feeling you are alone when it gets to the stressful parts of the semester. Having information online so that it can be accessed from home is fantastic, but their [sic] is not guarantee you are getting the right information down when you don't have

Another student described that although they value the social aspects of SNSs, they have a strong preference for face-to-face delivery with no mandated online component:

I find it difficult to concerntrate [sic] and learn when online and often get distracted, I learn much more efficiently by being in amongst what I am learning and having a physical presence at the university, it helps separate study life and social life. I go to lectures and tutorials to learn and use social media for socialising and entertainment.

A sub-group of students voiced their suspicion that the discussion around utilising SNSs as teaching stemmed from underlying motives to move towards entirely online learning models. Participants in each focus group expressed their concerns about the perceived push towards online learning. One student described this perceived shift as "terrifying" and others challenged that "this is not value for your money" ("you pay your HECS...just to sit at a computer?"). For all students in the focus groups, face-to-face learning was seen as their preferred model.

\section{Discussion}

Our results highlight the positive impacts SNSs can have for some students, mainly through the capacity to facilitate peer connectedness. However, students in this study raise underlying ethical issues regarding personal/educational technological overlap implicit in use of SNS sites external to the university for educative purposes, mainly boundary issues and moral/philosophical resistance to SNSs in higher education. These issues will be explored in relation to the extant literature. 
In their review of research on Facebook in higher education, Manca and Ranieri (2013) identify an underlying assumption that using Facebook meets the expectation of millennial learners for enhanced means of self-expression and information sharing. However, the introduction of demand-driven funding in Australian higher education has resulted in increased diversification of student cohorts (Norton, 2013). Increasingly, undergraduates at the institution from where this research emanates, and at other institutions, are not traditional Year 12 school leavers, but rather mature-age direct entrants. Statistics from 2015 show that only $62.71 \%$ of enrolled students are 24 and under, with the remaining third of students being over 25 . A comparison of responses by the youngest participants $(18-21,26.65 \%, n=93)$ and oldest participants (40 and above, $n=97$ ) shows significant variation in SNS usage rates $(97.8 \%, n=89$ as compared to $77.17 \%, n=71)$, engagement with Facebook $(96.7 \%, n=88$ as compared to $68.89 \%, n=62)$, use of SNSs in relation to studies (69.41\%, $n=49$ as compared to $44.4 \%, n=40)$, and how SNSs are used in relation to study ( $90 \%, n=63$ as compared to $58.82 \%, n=30$ for connecting to peers). These noteworthy differences highlight the need to move beyond blanket assumptions and one-size-fits all solutions about the needs and expectations of higher education students.

This study supports research (Irwin et al., 2012; Madge et al., 2009; McCarthy, 2010; Santos \& Cuta, 2015; Vivian et al., 2014) highlighting the strong capacity of SNSs for facilitating peer-to-peer connectedness. Student responses in this study concur with the observations of Madge et al. (p. 152) that SNSs are an important part of the "social glue" that supports peer connectedness. While the students in this study overwhelmingly report using SNSs in their studies as a way to connect to peers $(77.13 \%)$, it is important to note that a significant amount of students also report study-related usage: "connecting to content on Moodle (56.5\%) and "assess[ing] current research/information pertaining to [their] studies" (29.6\%). The exact nature of this use warrants further research attention.

Students in this study often identify face-to-face peer connectedness as their preferred option, qualifying that SNSs provide a useful substitute for students unable to attend, require support after hours or who are studying online. As such, this study reinforces Madge et al.’s (2009) assertion that:

[c]are must be taken not to over-privilege Facebook: it is only one aspect of students' social networking practices and clearly face-to-face relationships and interactions remain significant. (p. 152)

This study highlights the potential benefits of SNSs for online students as a way of revealing the isolation (and even alienation) that can be experienced by this cohort of students. Given rapidly increasing rates of online study in Australia (at 2013, 18\% of all higher education students were classified as off-campus and $9 \%$ were studying on a multimodal basis) (Norton \& Cherastidtham, 2014) and high attrition rates for this cohort, online students necessitate targeted interventions. Significant resourcing and support for online students has been implemented at the university where the research has been conducted since this data was collected, such as online mentoring program, a "Getting Started” Moodle site, and a Facebook page for online students. Positive feedback from students with regards to these initiatives highlights the opportunities for engagement (both social and academic) and retention through proactive and innovative SNS initiatives targeting online students.

Students reflect on their deliberate and distinctive variation between personal and educative use of SNSs on two levels: the intentional purpose and the image presented to other platform users. Manca and Ranieri (2013) reported similar observations from students who wanted separate social and educational spaces/spheres. Overwhelmingly, students in the present study make concrete delineations between SNSs for personal use as opposed to professional/study use. Some students had specific strategies to manage this, such as using different SNSs for specific purposes. A student's description of how connections with classmates about study-related issues can transition into more "personal” relationships (sending memes and funny videos) raises the issue of blurred boundaries/overlap of personal and educative identities.

The boundary blurring/overlap implicit in the use of SNSs widely used for social networking in the educational sphere presents ethical conundrums. The present study raises two particular challenges: firstly, issues about privacy and security, and secondly conflicts of interest implicit in friending student colleagues and staff on personal SNSs. Students' explicit desire to keep their identities separate suggests a potential lack of awareness of the public nature of SNS activity. A small but vocal majority of students also express 
their philosophical resistance to using SNSs due to concerns about their personal security and privacy. Literature on privacy settings in Facebook validates these concerns, revealing that many Facebook users are likely to be unaware of how opt-in default privacy settings work, meaning sensitive information could be widely available on the internet (Comer, McKelvey, \& McCurran, 2012). The potentially life-changing impacts of the emergence of the personal sphere into the public sphere is elucidated by the resignation of four candidates in the 2015 Canadian national elections due to their controversial past SNS postings on topics such as terrorism, abortion and legalisation of marijuana (CBC News, 2015).

Social work educators (Mukherjee \& Clark, 2012; Voshel \& Wesala, 2015) and nursing educators (Peck, 2014) explicitly outline the need for risk management strategies and SNS policies which acknowledge the ethical challenges SNSs pose personally and professionally for practitioners. While the institution where this research was conducted has social media guidelines, it would be interesting to explore staff and students' awareness and understanding of, and adherence to, these guidelines. In the midst of the digital revolution, should universities be doing more to educate students (and staff) about potentially undesirable, enduring SNS footprints they might leave behind, and the impacts this could have on their professional identity and careers? A minority of students in the online survey expressed their preference for the university (academic and administrative staff) to communicate through the official channels of Moodle (highlighting current tendencies for communication to occur through external SNSs). Students opposed to SNSs for privacy/ethical reasons risk missing out on valuable university information.

Interestingly, boyd and Ellison's (2007) explication of the privacy paradox (where individual post private information on public domains despite their awareness of public risks) suggests that knowledge does not necessarily equate with responsible behaviour. Mukherjee and Clark (2012) highlight a lack of connectivity between online and offline behaviour amongst social work students, where students (particularly younger students) are more likely to engage in potentially unethical behaviour with SNSs (such as friending a client). Could the same risks be inherent for staff members friending students on external SNSs? By encouraging students and staff to use SNSs such as Facebook to communicate with each other (either implicitly or explicitly), are universities making it difficult for students and staff to enforce divisions in their lives between the personal and professional, making risk seem less tangible? McEwan (2012, pp. 19-23) provides strategies for academics to regulate boundary challenges ("avoiding space invasion," "managing disclosure," "friending fairly," and "set availability expectations"). Her consideration of potential boundary issues and suggestions for praxis may serve as a starting point for robust discussion about using SNS appropriately and safely.

The minority voices of dissent and the ethical challenges emanating from this study raise provocative questions about the use of SNSs as formal and informal means of communication from a university to its students. Vivian et al.'s (2014) analysis of students' informal academic-related activities queried whose role it is to create informal peer groups - universities or students? Manca and Ranieri (2013) and Reed (2013) challenge assumptions that all younger students are digital natives who are comfortable with using SNSs and want to use it educationally. A limitation of the current research was a lack of clarity about the nature of SNSs students referred to. It would have been interesting to ascertain whether groups students referred to were initiated by students or staff, and whether university staff were members of external SNS sites set up by students for peer connectivity. Students in this survey, particularly the focus groups, highlight the importance of student-controlled and driven SNSs to enhance engagement.

Irwin et al. (2012) call for comparison studies between traditional LMSs and functions on SNSs such as Facebook to determine optimal platforms for student engagement and learning. In their comparison study of students' attitudes towards Moodle and Facebook as productive teaching platforms, Petrovic, Jeremic, Cirovic, Radojicic, and Milenkovic (2014) conclude that students prefer Moodle for study-related purposes and Facebook for its capacity to seek and provide peer-to-peer feedback. They suggest that students may feel more comfortable with Facebook than Moodle due to their familiarity with it. Some students in this study report being on Facebook not necessarily because they like it, but simply because of Facebook's ubiquitous reach as a communication tool. Rather than accepting Facebook as a given, should universities develop cultures where their own enhanced LMSs become the modus operandi for formal communication and learning delivery, and students can choose to use external SNSs for voluntary peer-to-peer connectivity? Ideally, the questions posed in this study will contribute to ongoing debates and discussion about the role of emerging technologies in higher education. 


\section{Implications and conclusion}

This study explored how students use and manage multiple SNSs for personal and study-related activities, and their perceptions of how SNSs use impacts their educational experiences. The findings suggest that the main purpose of SNS use in personal life is to connect with friends, and that SNSs can be used as a positive tool for facilitating peer-to-peer student connectedness, particularly for online students. However, there are significant age-related variations in engagement with SNSs. Students differentiate between personal and educative use of SNSs. Potential blurring of these personal and the educative identities may occur as a result of the overlap of these identities on SNSs (particularly when students engage with external SNSs rather than university-sanctioned LMSs), raising potential ethical challenges and dilemmas.

As the qualitative focus groups enabled more nuanced exploration of emerging themes, in-depth qualitative research is warranted. With regards to quantitative data, a larger sample size and research across universities could provide more comprehensive data for analysis. Future research seems warranted on the following topics: further exploration of how diverse cohorts engage with SNSs and LMSs (e.g., different age groups, study mode, socio-economic status); comparative exploration of usages/focus/content of LMSs, universitysanctioned SNSs, and student-led SNSs; student and academic perceptions of current LMS usage, and how LMSs can be harnessed to maximise both student connectedness and academic learning processes and outcomes.

The ethical challenges raised by this study will be best addressed by ongoing engagement with students about their experiences, perceptions, and preferences about learning. Additionally, this study highlights the need for constantly evolving development, trial and evaluation of innovative educational initiatives using SNSs, LMSs and technological applications which have not yet been designed, or possibly even imagined.

\section{Acknowledgements}

This research was supported by a grant from the Faculty of Education and Arts Small Research Grant Scheme, Federation University Australia. The authors would like to thank Cheryl Claridge and Peggy Hsu from Federation University Australia Library Services for their assistance with referencing.

\section{References}

boyd, d. m., \& Ellison, N. R. (2007) Social network sites: Definition, history, and scholarship. Journal of Computer-Mediated Education, 13(1), 210-230. doi:10.1111/j.1083-6101.2007.00393.x

Brady, K.P., Holcomb, L.B., \& Smith, B.V. (2010) The use of alternative social networking sites in higher educational settings: A case study of the e-learning benefits of Ning in education. Journal of Interactive Online Learning, 9(2), 151-170. Retrieved from http://www.ncolr.org/jiol/issues/pdf/9.2.4.pdf

Braun, V., \& Clarke, V. (2006). Using thematic analysis in psychology. Qualitative Research in Psychology, 3(2), 77-101. doi:10.1191/1478088706qp063oa

Buetow, S. (2010). Thematic analysis and its reconceptualization as 'saliency analysis.' Journal of Health Services Research and Policy, 15(2), 123-125. doi:10.1191/1478088706qp063oa

Capterra. (n.d.). Top LMS software [Infographic]. Retrieved from http://www.capterra.com/learningmanagement-system-software/\#infographic

CBC News. (2015, September 28). Liberal candidate Maria Manna steps down over posts questioning 9/11. Retrieved from http://www.cbc.ca/news/canada/british-columbia/canada-election-2015-liberalcandidate-facebook-1.3247636

Comer, R., McKelvey, N., \& Curran, K. (2012). Privacy and Facebook. International Journal of Engineering and Technology, 2(9), 1626-1630. Retrieved from http://www.ietjournals.org/archive/2012/sep_vol_2_no_9/sep_2012.php

Cowling, D. (2016, April 1). Social media statistics Australia - March 2016. Social Media News. Retrieved from http://www.socialmedianews.com.au/social-media-statistics-australia-march-2016/

Cuesta, M., Eklund, M., Rydin, I. \& Witt, A. (2015). Using Facebook as a co-learning community in higher education. Learning, Media and Technology, 41(1), 55-72.

doi:10.1080/17439884.2015.1064952 
Devlin, M. (2015). Learning and teaching plan 2015-2017: Enabling BOLD learning. Mt Helen: Federation University Australia. Retrieved from https://federation.edu.au/_data/assets/pdf_file/0007/227581/Learning-and-Teaching-Plan-201517_FINAL.pdf

Ernst \& Young. (2012). University of the Future: A thousand year old industry on the cusp of profound change. Retrieved from http://www.ey.com/Publication/vwLUAssets/University_of the future/\$FILE/University_of_the_futu re 2012.pdf

Facebook. (2016). Company info: Stats. Retrieved from http://newsroom.fb.com/company-info/

Federation University Australia. (n.d.). Learning management system. Retrieved from http://federation.edu.au/staff/learning-and-teaching/clipp/archive/lms

Fereday, J., \& Muir-Cochrane, E. (2006). Demonstrating rigor using thematic analysis: A hybrid approach of inductive and deductive coding and theme development. International Journal of Qualitative Methods, 5(1). Retrieved from http://www.ualberta.ca/ iiqm/backissues/5_1/pdf/fereday.pdf

Global Agenda Council on the Future of Universities. (2012). Global agenda council on the future of universities 2012-2014. World Economic Forum, Geneva. Retrieved from http://www3.weforum.org/docs/GAC/2013/Connect/WEF_GAC_Future_of_Universities_20122014_Connect.pdf

Irwin, C., Ball, L., Desbrow, B., \& Leveritt, M. (2012). Students’ perceptions of using Facebook as an interactive learning resource at university. Australasian Journal of Educational Technology, 28(7), 1221-1232. doi:10.14742/ajet.798

Jones, C., Ramanau, R., Cross, S. J., \& Healing, G. (2010). Net generation or digital natives: Is there a distinct new generation entering university? Computers \& Education, 54(3), 722-732. doi:10.1016/j.compedu.2009.09.022

Kabilan, M. K. (2016). Using Facebook as an e-portfolio in enhancing pre-service teachers' professional development. Australasian Journal of Educational Technology, 32(1), 19-31. doi:10.14742/ajet.2052

Kurkela, L. (2011). Systemic approach to learning paradigms and the use of social media in higher education. International Journal of Emerging Technologies in Learning, 6(14), 14-20. Retrieved from http://online-journals.org/i-jet/article/view/1616

Lord, S. (2016, January 27). Australian social media usage: Statistics 2015 [Infographic]. Retrieved from https://www.digital-next.com.au/blog/social-media-usage-in-australia-2015/

Madge, C., Meek, J., Wellens, J., \& Hooley, T. (2009). Facebook, social integration and informal learning at university: 'It is more for socialising and talking to friends about work than for actually doing work’. Learning, Media and Technology, 34(2), 141-155. doi:10.1080/17439880902923606

Maloney, S., Moss, A., \& Ilic, D. (2014). Social media in health professional education: A student perspective on user levels and prospective applications. Advances in Health Science Education, 19, 687-697. doi:10.1007/s10459-014-9495-7

Manca, S., \& Ranieri, M. (2013). Is it a suitable tool for learning? A critical review of the literature on Facebook as a Technology-Enhanced learning environment. Journal of Computer Assisted Learning, 29, 487-504. doi:10.111/jcal.12007

McCarthy, J. (2010). Blended learning environments: Using social networking sites to enhance the first year experience. Australasian Journal of Educational Technology, 26(6), 729-740. doi:10.14742/ajet.1039

McEwan, B. (2012). Managing boundaries in the web 2.0 classroom. New Directions for Teaching and Learning, 131, 15-28. doi:10.1002/tl

Mukherjee, D., \& Clark, J. (2012), Students’ participation in social networking sites: Implications for social work education. Journal of Teaching in Social Work Education, 32(2), 161-173. doi:10.1080/08841233.2012.669329

Norton, A. (2013). Keep the caps off! Student access and choice in higher education. Melbourne: The Grattan Institute. Retrieved from http://grattan.edu.au/wp-content/uploads/2014/03/195-Keep-thecaps-off.pdf

Norton, A., \& Cherastidtham, I. (2014), Mapping Australia higher education 2014-2015. Melbourne: Grattan Institute. Retrieved from http://grattan.edu.au/wp-content/uploads/2014/10/816-mappinghigher-education-2014.pdf

Peck, J. (2014). Social media in nursing education: Responsible integration for meaningful use. Educational Innovations, 53(3), 164-169. doi:10.3928/01484834-20140219-03 
Petrovic, N., Jeremic, V., Cirovic, M., Radojicic, Z., \& Milenkovic, N. (2014), Facebook vs. Moodle in practice. The American Journal of Distance Education, 28, 117-125. doi:10.1080/08923647.2014.896581

Ratneswary, R., \& Rasiah, V. (2014), Transformative higher education teaching and learning: Using social media in a team-based learning environment. Procedia - Social and Behavioural Sciences, 123, 369-379. doi:10.1016/j.sbspro.2014.01.1435

Reed, P. (2013). Hash tags and retweets: Using Twitter to aid community, communication and causal (informal) learning. Research in Learning Technology, 34(2), 157-174. doi:10.3402/rlt.v21i0.19692

Robbins, S. P., \& Singer, J. B. (2014). From the editor - The medium is the message: Integrating social media and social work education. Journal of Social Work Education, 50(3), 387-390. doi:10.1080/10437797.2014.916957

Santos, D., \& Cuta, M. (2015), The usage of social networks by university students (A survey of Facebook use patterns among young people). Anthropologia Integra, 6(1), 35-43. doi:10.5817/AI2015-1-35

Sensis. (2015). Sensis social media report May 2015: How Australian people and businesses are using social media. Retrieved from https://www.sensis.com.au/assets/PDFdirectory/Sensis_Social_Media_Report_2015.pdf

Social Networking Site (SNS). (2016). In Techopedia. Retrieved from https://www.techopedia.com/definition/4956/social-networking-site-sns

Tess, P. A. (2013). The role of social media in higher education classes (real and virtual): A literature review. Computers in Human Behavior, 29, A60-A68. doi:10.1016/j.chb.2012.12.032

Usher, K., et al. (2014). Australian health professionals use of social media. Collegian, 21(2), 95-101. doi:10.1016/j.colegn.2014.02.004

Vivian, R., Barnes, A., Geer, R., \& Wood, D. (2014), The academic journey of university students on Facebook: an analysis of informal academic-related activity over a semester. Research in Learning Technology, 22. doi:10.3402/rlt.v22.24681

Voshel, E. H., \& Wesala, A. (2015). Social media and social work ethics: Determining best practice in an ambiguous reality. Journal of Social Work Values and Ethics, 12(1), 67-76. Retrieved from http://jswve.org/download/spring_2015,_vol._12,_no._1/JSWVE-12-1-Spring-2015Full\%20publication-revised-11-13-15.pdf

Wang, Z., Tchernev, J. M., \& Solloway, T. (2012). A dynamic longitudinal examination of social media use, needs, and gratifications among college students. Computers in Human Behavior, 28(5), 18291839. doi:10.1016/j.ehb.2012.05.001

Corresponding author: Dr Christina Sadowski, c.sadowski@federation.edu.au

Australasian Journal of Educational Technology (c) 2017.

Please cite as: Sadowski, C., Pediatis, M., \& Townsend, R. (2017). University students’ perceptions of social networking sites (SNSs) in their educational experiences at a regional Australian university. Australasian Journal of Educational Technology, 33(5), 77-90. https://doi.org/10.14742/ajet.2927 